\title{
Organic pollutants in wastewater and its remediation approaches using graphene adsorbent
}

\author{
Krishna Rawat \\ SESD, Central University of Gujarat, Gandhinagar, Gujarat, India \\ Corresponding author e-mail: evskrishna@gmail.com
}

(Received: 19/05/2021; Revised: 10/09/2021; Accepted: 20/10/2021)

\begin{abstract}
The release of contaminants/pollutants in an environment above permissible limits has been a matter of concern since the past. They are a prime source of environmental pollution and cause health issues to the general public and other living creatures. In the same series, organic pollutants are serious concern to the surrounding site of release, among them persistent organic pollutants are more threatening to our environment. Organic pollutants contaminate the surrounding where they are released, thus their remediation is of prime importance to save our environment and assure health to living being. Therefore, this paper attempts to bring forward the organic pollutants in wastewater and highlights the possible remediation approaches that can be adopted to assure a healthy environment.
\end{abstract}

Keywords: Organic pollutants, contamination, remediation, persistent organic pollutants.

\section{INTRODUCTION}

Earth's major portion is covered with water yet out of only a small fraction is freshwater or potable water that total water available on earth is useful to sustain life. With demographic increase water demand has increased majorly, while other factors include industrial development, \& other developmental activities, etc. We all are aware of the importance of water and it's a matter of concern as many of our states are facing water stress and reports confirm this graph increasing in near future in almost all the areas of the country. There are many sources from where wastewater is generated such as industrial, agriculture, municipal, etc. Municipal water consists of a high organic load in form of microbes, with another chemical that is used in daily activities, pharmaceuticals, etc. Marc et al., (2005), Ibrahim, (2012). While industrial wastewater has a high load of different toxic metals, compounds of organic and inorganic nature, chlorinated by-products, dyes, etc. Agricultural wastewater generally consists of pesticides, weedicides, insecticides, organic pollutants etc. Ellis, (2004); Martynas et al., (2013). The increased production of this pollutant from any source has a major impact on the biota and the environment that needs a check and remediation on time. These wastes are great challenge to be faced for water quality management. Thus, we need to develop some strategies to treat and reuse wastewater in all possible ways. A brief of some common organic pollutants and remediation using nanoparticles:

\section{i. Dyes}

Dyes are coloring agents used in various industries such as textiles, cosmetics, printing, etc. This generates enormous contaminants in the wastewater. According to Allen and Koumanova (2003) annually approx $7 * 10^{5}$ tonnes of dye waste is generated from commercially available dye stock of more than 10,000 dyes. Among all kinds of industries contributes maximum discharge of dyes in wastewater making their way to rivers, streams, groundwater and the surrounding environment. Dyes may cause cancer, skin irritation, allergies, etc. This problem is more serious as dyes have complex aromatic structures due to which their degradation is difficult (Pearce et al., 2003). Depending upon the concentration of dyes exposed to organism and the exposure time, dyes may show acute or chronic effects in the organism. Mishra and Tripathy (1993) classified dyes into three groups anionic dyes, cationic dyes, and non-ionic dyes. Anionic dyes are reactive acidic dyes while cationic dyes are basic dyes and non-ionic are dispersive dyes. Thus, keeping in mind the essentiality of dye removal these industries need to treat effluent-containing dye before its disposal. Scientific techniques must be applied to treat the wastewater effectively. In this direction adsorption process is gaining importance to treat such effluents, owing to its low cost (Kapdan and Kargi 2002). Various nanomaterials have been used up efficiently to treat organic and inorganic contaminants from wastewater effluents. These nano materials can be carbon nanotubes, metals, metal oxides or plant-based materials, etc. Currently graphene is gaining popularity owing to its stable chemical structure and physic-chemical properties 
(Amin et al., 2014; Gautam and Chattopadhyaya, 2016). Many studies have been done for pollutant removal such as dyes, heavy metals, pharmaceuticals, organic pollutants, etc. using graphene (Robati et al., 2016; Sharma and Das, 2013; Wang et al.,2014; Janik et al., 2018; Wei et al., 2018; Wu et al.,2018; Zhang et al., 2018; Nam et al., 2015).

\section{ii. Pesticides}

In agriculture to protect plants from pests, fungi, insects, weeds, etc. wide usage of pesticide is common worldwide. This has resulted in the dispersal of pesticides in water bodies and terrestrial land through runoff or directly during the spraying of pesticides in crops. They significantly harm the environment they released into also impose toxic effects on the living being (Nasrabadi et al., 2011; Maddah and Hasanzadeh, 2017). Adsorption technique may be implied for treatment of pesticides contaminated water; many studies have been done using this technique. Pesticide adsorption using graphene has been studied by Maliyekkal et al., (2012). Gupta et al., 2015 studied persistent halocarbon pesticides removal using graphene. A study by Liu et al., (2013) concluded graphene-coated silica was much efficient for pesticide removal from water bodies. Many other types of research proved graphene nanomaterial much reliable sorbent for wastewater treatment (Zhang et al., 2015; Wu et al., 2011).

\section{iii. Pharmaceutical chemicals}

The pharmaceutical industry is one of the most important and fastest growing industries in India. In terms of volume, it is third-largest industry in India (Kumar et al., 2010). Pharmaceutical compounds are designed for producing therapeutic effects in organism. Since pharmaceutical compounds are bioactive and persistent, they are considered as emerging contaminants in the present scenario. Thus, their release in environment has a toxic impact to the living organism (Grassi et al., 2013 Manciocco et al., 2014). Pharmaceutical compounds often cause synergistic impacts as these compounds are released into environment in a mixture form (Cleuvers, 2003). Additionally, pharmaceutical industries also add on their effluents to the stream after partial treatment that leads to the release of pharmaceutical compounds into the environment acting as environmental pollutant. These compounds also make their way into environment when they are expelled out in feces, urinated, leakage from sewer lines, runoff from landfill sites and animal waste, etc. A huge amount of waste is generated during the maintenance and manufacturing of pharmaceutical compounds. To date no limit has been set up by the Bureau of Indian Standards (BIS) for the release of pharmaceuticals in wastewater or other water bodies. However, in America, some pharmaceutical compounds have been listed in the most contaminating environmental contaminants (Patneedi and Prasadu, 2015).

Thus, to remove this contaminant from wastewater adsorption technique seems to be more promising and among new absorbents graphene has gained much attention in current years owing to its large surface area, small size, remarkable electrical conductivities, high mechanical strength etc. (Chowdhury et al., 2014). Currently, graphene has evolved as much promising substitute that has shown more potential as compared to carbon for wastewater treatment. Sophia et al., 2016 discussed several types of research stating the use of graphene usage for pharmaceutical compounds removal from wastewater.

\section{iv. Hydrocarbons}

Compounds of hydrogen and carbon are known as hydrocarbons they are important part of our daily life. Mainly they are grouped into three categories such as saturated, unsaturated, and aromatic hydrocarbons depending upon their carbon-carbon bond. There is single carbon-carbon or carbon-hydrogen bond in case of saturated hydrocarbons, while in case of unsaturated hydrocarbons there are multiple bonds i.e., two or three. While aromatic hydrocarbons are cyclic compounds. Hydrocarbons are widely used in many products useful to mankind, this, in turn, leads to their proportional release in the environment, contaminating the environment. They have high solubility in water therefore have high availability to aquatic biota (Neff, 2002). Thus, they are a matter of great concern. Current research for remediation of hydrocarbon contaminated water bodies mainly deals with biological approaches, membrane filtration, thermal and oxidation process (Bustillo-Lecompte et al., 2018; Ma et al., 2018; Xue et al., 2018). Adsorption based processes are currently very popular for wastewater remediation because of their cost-effectiveness and high efficiency. Graphene-based materials are very popular absorbents for wide contaminants in wastewater (Wang and Zhao, 2016). Many types of research have been done using graphene absorbent for the removal of hydrocarbon including PAH hydrocarbon, soluble hydrocarbons, petroleum hydrocarbons, etc. from wastewater (Flores-Chaparro et al., 2020; Yang et al., 2017; Song et al., 2019).

\section{v. Organic compounds}

Everyday copious amount of common organic waste consisting of carbon, hydrogen such as protein, fats, carbohydrates, etc. that are biodegradable make their way to wastewater. Major sources of organic waste are synthetic sources or from animal or plants. They make their way into waste water from industrial or agricultural sources or human waste, food, cosmetics, pharmaceuticals, household waste, etc. Their heavy load in water causes oxygen depletion in water bodies as major fraction of oxygen is consumed by microbes as BOD for degradation of organic products thus making low availability of oxygen to other aquatic organisms. Also, in many cases, their low concentration may not have acute impacts but they may have long term impacts because of their persistent nature. Thus, organic compounds load must be checked and treated in wastewater before making their way to other water bodies. There are various conventional processes such as membrane filtration etc. for treatment of organic 
compounds in wastewater but they are not satisfactory due to some limits such as technical performances, degradation or deterioration of efficiency of absorbents etc. To substitute this various complex treatment processes were adopted such as oxidation, ozonation, nanofiltration but they too had limits owing to the huge cost of implementation, maintenance difficulties, risk of secondary pollutants. Thus, we need to work out some remediation processes to cross these limits. Various studies have reported for removal of organic pollutants, graphene and its based materials are novel and efficient material, which works out without interfering with natural processes, as they are carbonaceous materials. Thus, they prove to be bright scope for environmental remediation using graphene and its based materials (Zhang et al., 2020). Cheng et al., 2018 studied the usage of reduced graphene oxides for removal of organic compounds from wastewater. Bharath et al., 2017 studied the removal of organic and inorganic pollutants using graphene-based nanocomposite from wastewater. Thakur et al., 2019 reviewed graphene and graphene oxide-based composites usage for removal of organic pollutants from wastewater and stated it is suitable for catalysis and adsorption of organic contaminants from wastewater.

\section{vi. Biological pollutants in wastewater}

Biological contaminants may include insects, microorganisms such as bacteria, viruses, plants pollen grains, animal saliva organism, etc. and many more forms. There are many sources of origin and transmission of biological pollutants. Wastewater serves as a breeding ground for biological pollutants and contaminate wastewater manyfolds. Thus, they need to be treated to avoid the severity of environmental pollution. In this sphere of research adsorption by graphene had yielded effective results. Smith and Rodrigues (2015) reviewed the removal of biological contaminants from water bodies and discussed the efficient removal of biological bodies (bacteria, viruses etc.) using graphene nanomaterial. Bandara et al., 2019 in his study demonstrated the efficient removal of microbes efficiently using graphene oxide from water. Abdelmeguid et al., 2017 demonstrated the removal of biological contaminants from water using graphene oxide with efficiency of $99 \%$ removal with a low dose of $40 \mathrm{mg} / \mathrm{L}$. Gollavelli et al., studied the removal of E. coli bacteria using graphene and found it $100 \%$ efficient in bacterial removal from water. Similarly, many types of research have been done for the removal of biological contaminates from wastewater using graphene and its based materials (Liu et al., 2011; Akhavan et al., 2010; Hu et al., 2010).

\section{Methodology and monitoring}

Organic pollutant's presence can be identified by various standard methods such as evaluation of BOD, COD, TOC, etc. In addition to it Mass spectrometry chromatography can be adopted for the identification of organic pollutants in wastewater.

\section{Remediation Techniques}

Organic pollutants are a great threat to wastewater that is generated as it has the potential to deplete dissolved oxygen this worse the water quality and disturbs the aquatic life. In addition to it some of the organic waste can be toxic causing to the aquatic environment for a prolonged period. Thus, there is great need to treat these constituents before wastewater disposal. In this direction various biological and chemical methods also, their combination has been worked out to solve the problem but they have their limitation thus remediation of organic pollutants by adsorption techniques has gained popularity. In this field, further advancements have been done using nanoparticles usage as adsorbents. This has come up as very promising technique to treat wastewater loaded with organic waste. Further graphene nano adsorbents serve as a great technology for solving the problem. One of the positive aspect of using nanomaterials is that they have high potential for adsorbing organic waste and further can be regenerated.

Desorption and Regeneration of graphene nanoadsorbents

To reduce the cost of nanoparticle usage for removal of pollutants from contaminated wastewater, their regeneration is most important. This serves two objectives one is the restoration of adsorptive capacity of absorbent, while the other is recovering valuable components present in the adsorbed phase. $\mathrm{NaOH}$ has been most effective regenerating agent for many nano adsorbent's regeneration studies (Lata and Samadder, 2016). pH plays an important role in the desorption and regeneration of adsorbents (Ali, 2012). Sharma et al., 2010 stated reuse or regenerated nano absorbents for removal of metallic pollutants. There are many researchers who reported for regeneration of graphenebased adsorbents, using different procedures (Jiang et al., 2016; Zhang et al., 2013; Liu et al., 2018).

\section{CONCLUSION}

Adsorption has come up to be one of the most suitable wastewater treatment technology, owing to its easy operation, and wide range of adsorbents for contamination removal from the substrate. Also, they are applicable for wide range of water pollutants such as organic, inorganic, biological, pharmaceutical wastes, etc. Despite having so many benefits this process is not much preferred at commercial levels because of its some the limitations. Thus, in order to cope up with it, nanotechnology is bright future for the adsorption process. In this field graphene proves to be multifunctional material as an absorbent for the expulsion of wastewater pollutants, thus they present to be new prospects for developing advanced wastewater strategies. In comparison to other nanoparticles graphene has turned to be the more preferred choice for wastewater treatment owing to its remarkable characteristics. Yet there is a bigger challenge to make them cost effective and their large-scale production. 


\section{FUTURE PROSPECTUS}

The current review of literature brings to light that not much work is done using graphene for emerging contaminants that must be carried out. Regeneration studies of graphene are limited that must be explored to enhance the better utilization of materials on land. Lastly, evaluation studies of material impact on environment must be carried out in future. Thus, we conclude this review paper with the view that it enhances the researchers' knowledge for nanomaterial graphene, enlightening them about new future research ideas for their upcoming research.

\section{ACKNOWLEDGMENT}

I want to express my deep appreciation and thanks to my colleague who inspired me to work on such an environment beneficial topic. The environment is in limelight all time; however, we work hard, but still my problems need attention to be paid on. In this light present work was carried out to bring up some solutions to the critical environmental issues. I wish to express my appreciation to my colleague for sharing their wisdom during work. Finally, I extend my thanks to my friends and family for their constant support and well wishes.

\section{REFERENCES}

Aboubaraka, A. E., Aboelfetoh, E. F., and Ebeid, E. Z. M. 2017. Coagulation effectiveness of graphene oxide for the removal of turbidity from raw surface water. 738-746. doi.org/10.1016/j.chemosphere.2017.04.137.

Akhavan, O., Ghaderi, E. 2010. Toxicity of graphene and graphene oxide nanowalls against bacteria. ACS Nano, 4: 5731-5736.

Allen, S.J., Koumanova, B. 2003. Decolourisation of water/wastewater using adsorption. J Uni Chem Technol Metall 40:175-192.

Ali, I., 2012. New generation adsorbents for water treatment. Chem. Rev. 5073e5091.

Amin, M.T., Alazba, A.A., Manzoor, U., 2014 Review of removal of pollutants from water/wastewater using different types of nanomaterials. Advance Material Science and Engineering. 825910.

Bandara, P. C., Nadres, E. T., Peña-Bahamonde, J., \& Rodrigues, D. F. 2019. Impact of water chemistry, shelf-life, and regeneration in the removal of different chemical and biological contaminants in water by a model Polymeric Graphene Oxide Nanocomposite Membrane Coating. Journal of Water Process Engineering, 32: 100967. doi:10.1016/j.jwpe.2019.100967.

Bharath, G., Alhseinat, E., Ponpandian, N., Khan, M. A., Siddiqui, M. R., Ahmed, F., \& Alsharaeh, E. H. 2017. Development of adsorption and electrosorption techniques for removal of organic and inorganic pollutants from wastewater using novel magnetite/porous graphene-based nanocomposites. Separation and Purification Technology, 188: 206-218. doi:10.1016/j.seppur.2017.07.024.

Cheng, C., Cai, Y., Guan, G., Yeo, L., \& Wang, D. 2018. Hydrophobic-Force-Driven Removal of Organic Compounds from Water by Reduced Graphene Oxides Generated in Agarose Hydrogels. Angewandte Chemie International Edition. Doi.org/ 10.1002/anie.201803834.

Chowdhury, S., Balasubramanian,R. 2014) Recent advances in the use of graphene family nanoadsorbents for removal of toxic pollutants from wastewater, Adv. Colloid Interface Sci. 204: 35-56, doi.org/10.1016/j. cis.2013.12.005. 24412086.

Cleuvers, M. 2003. Aquatic ecotoxicity of pharmaceuticals including the assessment of combination effects. Toxicol. Lett.142(3): 185194. doi. org/10.1016/S0378-4274(03)00068-7. 12691712.

Flores-Chaparro, C. E., Castilho, C. J., Külaots, I., Hurt, R. H., and Rangel-Mendez, J. R. 2020. Pillared graphene oxide composite as an adsorbent of soluble hydrocarbons in water: $\mathrm{pH}$ and organic matter effects. Journal of Environmental Management, 259:110044. doi:10.1016/j.jenvman.2019.110044.

Hammer, M. J. 1975. Water and Waste-Water Technology. Beijing: John Wiley \& Sons

Geim, A.K., Novoselov, K.S., 2007. The rise of graphene. Nat. Mater. 6: 183-191. doi.org/10.1038/nmat1849.

Gautam, R.K. Chattopadhyaya, M.C., 2016. Nanomaterials for wastewater remediation. Wiley Interscience, Oxford.

Gollavelli, G., Chang, C.-C., \& Ling, Y.-C. 2013. Facile Synthesis of Smart Magnetic Graphene for Safe Drinking Water: Heavy Metal Removal and Disinfection Control. ACS Sustainable Chemistry \& Engineering, 1(5): 462-472. dx.doi.org/10.1021/sc300112z

Grassi, M. Rizzo, L. Farina, A. 2013. Endocrine disruptors compounds, pharmaceuticals and personal care products in urban wastewater: implications for agricultural reuse and their removal by adsorption process, Environ. Sci. Pollut. Res. 20 (6):3616-3628, doi.org/10.1007/s11356-013-1636-7. 23532534.

Hu, W., Peng, C., Luo, W., Lv, M., Li, X., Li, D., Huang, Q., Fan, C. 2010. Graphene-Based Antibacterial Paper. ACS Nano, 4: 4317-4323.

Janik, P., Zawisza, B., Talik, E., Sitko, R., 2018. Selective adsorption and determination of hexavalent chromium ions using graphene oxide modified with amino silanes. Microchim. Acta 185, 117. doi.org/10.1007/s00604-017-2640-2.

Jiang, L., Liu, Y., Zeng, G., Xiao, F., Hu, X., Hu, X., Wang, H., Li, T., Zhou, L., Tan, X. 2016. Removal of $17 \beta$-estradiol by few-layered graphene oxide nanosheets fromaqueous solutions: external influence and adsorption 
mechanism. Chem. Eng. J. 284, 93-102. doi.org/10.1016/j.cej.2015.08.139.

Kapdan I. K. and Kargi F. 2002. Simultaneous biodegrdation and adsorption of texile dye stuff in an activated sludge unit. Process Bio Chem 37: 973-981.

Kemp, K.C., Seema, H., Saleh, M., Le, N.H., Mahesh, K., Chandra, V., Kim, K.S., 2013. Environmental applications using graphene composites: water remediation and gas adsorption. Nanoscale 5: 3149-3171. doi.org/10.1039/C3NR33708A.

Khalid, A., Zubair, M., Ihsanullah, 2018. A comparative study on the adsorption of Eriochrome black T dye from aqueous solution on graphene and acidmodified graphene. Arabian J. Sci. Eng. 43: 2167-2179. doi.org/10.1007/s13369-017-2543-x.

Kumar, A., Bisht, B S., Joshi, V.D., Singh, A.K., Talwar, A. 2010. Journal of Human Ecology, 32(3): 169.

Lata, S., and Samadder, S. R. 2016. Removal of arsenic from water using nano adsorbents and challenges: A review. Journal of Environmental Management, 166: 387-406. doi.org/10.1016/j.jenvman.2015.10.039.

Liu, S., Zeng, T. H., Hofmann, M., Burcombe, E., Wei, J., Jiang, R., Kong, J., Chen, Y. 2011. Antibacterial activity of graphite, graphite oxide, graphene oxide and reduced graphene oxide: membrane and oxidative stress. ACS Nano 5: 6971-6980.

Liu, S., Ge, H., Wang, C., Zou, Y., Liu, J., 2018. Agricultural waste/graphene oxide 3D bioadsorbent for highly efficient removal of methylene blue from water pollution. Sci. Total Environ. 628-629, 959-968. doi.org/https://doi.org/10.1016/j.

Liu, F., Chung, S., Oh, G., Seo, T.S., 2012. Threedimensional graphene oxide nanostructure for fast and efficient water-soluble dye removal. ACS Appl. Mater. Interfaces 4: 922-927. doi.org/10.1021/am201590z.

Liu, X., Zhang, H., Ma, Y., Wu, X., Meng, L., Guo, Y., Yu, G., Liu, Y., 2013. Graphene-coated silica as a highly efficient sorbent for residual organophosphorus pesticides in water. J. Mater. Chem. A., 1: 1875- 1884.

Maddah, B., Hasanzadeh, M., 2017. Fe3O4/CNT Magnetic Nanocomposites as Adsorbents to Remove Organophosphorus Pesticides from Environmental Water", Int. J. Nanosci. Nanotechnol. 13: 139-149.

Maliyekkal, S. M., Sreeprasad, T., Krishnan, D., Kouser, S., Mishra, A. K., Waghmare, U. V., Pradeep, T., 2012. Graphene: a reusable substrate for unprecedented adsorption of pesticides. Small, 9: 273-283.

Manciocco, A. Calamandrei, G. Alleva, E. 2014) Global warming and environmental contaminants in aquatic organisms: the need of the ethotoxicology approach, Chemosphere 100:1-7. doi.org/10.1016/j.chemosphere.2013.12.072. 24480426.

Mishra, G. Tripathy, M. 1993. A critical review of the treatment for decolorization of dye wastewater. Colourage, 40:35-38.

Nam, S.W., Jung, C., Li, H., Yu, M., Flora, J.R.V., Boateng, L.K., Her, N., Zoh, K.D., Yoon, Y., 2015. Adsorption characteristics of diclofenac and sulfamethoxazole to grapheme oxide in aqueous solution. Chemosphere, 136: 20-26. doi.org/10.1016/j.

Nasrabadi, T., Bidhendi, G. N., Karbassi, A., Grathwohl, P., Mehrdadi, N., 2011. Impact of major organophosphate pesticides used in agriculture to surface water and sediment quality (Southern Caspian Sea basin, Haraz River. Environ. Earth. sci., 63: 873-883.

Patneedi, C. B. and Prasadu, K.D. 2015. Impact of pharmaceutical wastes on human life and environment. Rasayan Journal Chemistry 8(1): 67-70.

Pearce, C.I., Lloyd, J.R., Guthrie, J.T. 2003. The removal of colour from textile wastewater using whole bacterial cells: a review. Dyes pigment, 58: 179196.

Robati, D., Mirza, B., Rajabi, M., Moradi, O., Tyagi, I., Agarwal, S., Gupta, V.K., 2016. Removal of hazardous dyes-BR 12 and methyl orange using graphene oxide as an adsorbent from aqueous phase. Chem. Eng. J. 284: 687-697. doi.org/10.1016/j.cej.2015.08.131.

Sen Gupta, S., Chakraborty, I., Maliyekkal, S. M., Adit Mark, T., Pandey, D. K., Das, S. K., Pradeep, T., 2015. Simultaneous dehalogenation and removal of persistent halocarbon pesticides from water using graphene nanocomposites: A case study of lindane. Sustain. Chem. Eng., 3: 1155-1163.

Sharma, P., Das, M.R., 2013. Removal of a cationic dye from aqueous solution using graphene oxide nanosheets: investigation of adsorption parameters. J. Chem. Eng. 151-158. doi.org/10.1021/je301020n.

Sharma, A., Verma, N., Sharma, A., Deva, D., Sankararamakrishnan, N., 2010. Iron doped phenolic resin based activated carbon micro and nanoparticles by milling: synthesis, characterization and application in arsenic removal. Chem. Eng. Sci. 65: 3591e3601.

Smith, S. C., \& Rodrigues, D. F. 2015. Carbon-based nanomaterials for removal of chemical and biological contaminants from water: A review of mechanisms and applications. Carbon, 91: 122143. doi.org/10.1016/j.carbon.2015.04.043.

Song, B., Tang, J., Zhen, M., and Liu, X. 2019. Influence of graphene oxide and biochar on anaerobic degradation of petroleum hydrocarbons. Journal of Bioscience and Bioengineering. doi:10.1016/j.jbiosc.2019.01.006. 
Sophia, A. C., Lima,E.C., Allaudeen, N. and Rajan, S. 2016. Application of graphene-based materials for adsorption of pharmaceutical traces from water and wastewater- a review, Desalination and Water Treatment, 57:57, 27573-27586, 10.1080/19443994.2016.1172989.

Thakur, K., \& Kandasubramanian, B. 2019. Graphene and Graphene Oxide-Based Composites for Removal of Organic Pollutants: A Review. Journal of Chemical and Engineering Data. doi:10.1021/acs.jced.8b01057.

Wang, J., Chen, Z., Chen, B., 2014. Adsorption of polycyclic aromatic hydrocarbons by graphene and graphene oxide nanosheets. Environ. Sci. Technol. 48:4817-4825. doi.org/10.1021/es405227u.

Wei, M., Chai, H., Cao, Y., Jia, D., 2018. Sulfonated graphene oxide as an adsorbent for removal of $\mathrm{Pb}^{2+}$ and methylene blue. J. Colloid Interface Sci. 524: 297-305. doi.org/10.1016/j.jcis.2018.03.094.

Wu, L. K., Wu, H., Zhang, H. B., Cao, H. Z., Hou, G.Y., Tang, Y. P., Zheng, G. Q., 2018. Graphene oxide $\mathrm{CuFe} 2 \mathrm{O} 4$ foam as an efficient absorbent for arsenic removal from water. Chem. Eng. J. 334: 1808-1819. doi.org/10.1016/j.cej.

Wu, Q., Zhao, G., Feng, C., Wang, C., Wang, Z., 2011. Preparation of a graphene-based magnetic nanocomposite for the extraction of carbamate pesticides from environmental water samples. $J$. Chromatogr. A, 1218: 7936-7942.
Yang, X., Cai, H., Bao, M., Yu, J., Lu, J., \& Li, Y. 2017. Highly Efficient Photocatalytic Remediation of Simulated Polycyclic Aromatic Hydrocarbons (PAHs) Contaminated Wastewater under Visible Light Irradiation by Graphene Oxide Enwrapped Ag3 PO4 Composite. Chinese Journal of Chemistry, 35(10), 1549-1558. DOI: 10.1002/cjoc.201700202.

Zhang, Y., Cui, W., An, W., Liu, L., Liang, Y., Zhu, Y., 2018. Combination of photoelectrocatalysis and adsorption for removal of bisphenol A over TiO2 -graphene hydrogel with 3D network structure. Appl. Catal. B Environ. 221: 36-46. doi.org/10.1016/j.apcatb.2017.08.076.

Zhang, S., Li, B., Wang, X., Zhao, G., Hu, B., Lu, Z., Wang, X. 2020. Recent developments of twodimensional graphene-based composites in visible-light photocatalysis for eliminating persistent organic pollutants from wastewater. Chemical Engineering Journal, 124642. doi:10.1016/j.cej.2020.124642.

Zhang, C., Zhang, R. Z., Ma, Y. Q., Guan, W. B., Wu, X. L., Liu, X., Li, H., Du, Y. L., Pan, C. P., 2015. Preparation of Cellulose/Graphene Composite and Its Applications for Triazine Pesticides Adsorption from Water. Sustain. Chem. Eng., 3: 396-405.

Zhang, Y., Tang, Y., Li, S., Yu, S., 2013. Sorption and removal of tetrabromobisphenol A from solution by graphene oxide. Chem. Eng. J. 222: 94-100. doi.org/10.1016/j.cej.2013.02.027.

Citation: Krishna Rawat 2021. Organic pollutants in wastewater and its remediation approaches using graphene adsorbent. International Journal of Agricultural and Applied Sciences, 2(2):8-13. https://doi.org/10.52804/ijaas2021.222

Copyright: () Krishna Rawat 2021. Creative Commons Attribution 4.0 International License. IJAAS allows unrestricted use, reproduction, and distribution of this article in any medium by providing adequate credit to the author(s) and the source of publication. 